\title{
Suplementação alimentar de novilhas no pós-desmame: efeitos no crescimento e desempenho reprodutivo
}

\author{
Paulo Schermann Azambuja ${ }^{1}$, Alcides Pilau ${ }^{1}$, José Fernando Piva Lobato²
}

\author{
1 Pós-Graduação em Zootecnia, Faculdade de Agronomia/UFRGS. Bolsista CNPq. \\ 2 Departamento de Zootecnia, Faculdade de Agronomia/UFRGS. Bolsista IA CNPq. Caixa Postal 15100. CEP: 90001-970, Porto Alegre, RS.
}

RESUMO - Foram avaliados nesta pesquisa o desenvolvimento a partir da desmama e o desempenho reprodutivo aos 13/15 meses de idade de 56 bezerras de corte Hereford e 52 Braford, com médias de peso corporal de $126 \mathrm{~kg}$, de escore de condição corporal de 2,5 pontos e seis meses de idade. Os animais foram mantidos em pastagem nativa por 45 dias e, após este período, distribuídos em três sistemas alimentares (SA) por um período de 80 dias (1/6/2001 a 20/8/2001): CN+FA - suplementação em pastagem nativa $(\mathrm{CN})$ com farelo de arroz desengordurado (FA); $\mathrm{SB}+\mathrm{FA}$ - confinamento a céu aberto com silagem de sorgo de baixa qualidade (SB) e FA; SS+RC - confinamento a céu aberto com silagem de sorgo de qualidade superior e ração comercial (RC). Após o término dos SA, os animais permaneceram, em lote único, em pastagem de azevém (Lolium multiflorum Lam) até final de novembro e em pastagem nativa durante o período de acasalamento. Foram avaliados peso corporal (PC), escore de condição corporal (ECC), ganho de peso médio diário (GMD) e taxa de prenhez (TP). Durante os SA, o GMD das novilhas $\mathrm{SS}+\mathrm{RC}(0,480 \mathrm{~kg})$ foi superior aos demais e das $\mathrm{SB}+\mathrm{FA}(0,252 \mathrm{~kg})$, superior às CN+FA $(0,174 \mathrm{~kg})$. Na pastagem de azevém, os ganhos foram semelhantes $(0,436 \mathrm{~kg} / \mathrm{dia})$, assim como no período de acasalamento $(0,519 \mathrm{~kg} / \mathrm{dia})$. No período de acasalamento, as novilhas $\mathrm{SS}+\mathrm{RC}$ foram mais pesadas e tiveram maior ECC em relação à do $\mathrm{CN}+\mathrm{FA}$. A TP média foi de $17 \%$, sem diferenças entre os SA. As novilhas Braford apresentaram maior PV e CC ao acasalamento e maior TP que as Hereford. As novilhas prenhes foram as mais pesadas e de maior ECC à desmama, ao início e fim dos SA e do acasalamento, as mais velhas e com maiores GMD no período avaliado.

Palavras-chave: bezerras, condição corporal, prenhez, recria, suplementação

\section{Feeding supplementation of female calves after weaning: effects on the growth and reproductive performance}

\begin{abstract}
The objective of this work was to evaluate the development post weaning and the reproductive performance at 13/15 months old of 56 Hereford and 52 Braford female calves, with average body weight of $126 \mathrm{~kg}$, body condition score of 2.5 and six months old. The animals were kept in natural pasture $(\mathrm{CN})$ during 45 days and after this period, allotted to three feeding systems (SA) for a period of 80 days (06/01/2001 to 08/20/2001): CN + FA - supplementation of CN with defatted rice bran (FA); SB + FA - open sky feedlot with low quality sorghum silage (SB) and FA; SS + RC - open sky feedlot with higher quality sorghum silage (SS) and commercial concentrate (RC). After the end of SA, the animals were kept, as a unique group, on ryegrass pasture (Lolium multiflorum Lam) until end of November and on natural pasture during the mating period. Body weight $(\mathrm{BW})$, body condition score (BCS), average weight gain (AWG) and pregnancy rate (PR) were evaluated. During the $\mathrm{SA}$, the AWG of the SS + RC $(0.480 \mathrm{~kg})$ was higher than the other systems, and of the SB + FA $(0.252 \mathrm{~kg})$ higher than CN + FA $(0.174 \mathrm{~kg})$. On ryegrass pasture, AWG were similar $(0.436 \mathrm{~kg})$, as well as during the mating period $(0.519 \mathrm{~kg})$. In the mating period, the heifers SS + RC were heavier and had higher BCS than CN + FA system. Mean pregnancy rate was $17 \%$, without differences between SA. Braford heifers had higher BW and BCS at mating and higher PR than Hereford. The pregnant heifers were heavier and had better BCS at weaning, at beginning and end of the SA and mating time, the oldest ones and with higher AWG during the experiment than the non pregnant.
\end{abstract}

Key Words: body condition, female calves, pregnancy, rearing, supplementation

\section{Introdução}

A redução da idade ao primeiro serviço de novilhas para 24 a 26 meses, "sistema dois anos", e na seqüência, para os 13 a 15 meses, "sistema um ano" (Rocha \& Lobato, 2002a), ocupa papel de destaque no manejo e na eficiência de rebanhos de ciclo completo. Entretanto, ambos devem estar associados a índices de fertilidade 
em torno de $80 \%$ no rebanho de cria adulto (Beretta et al., 2001).

O primeiro serviço de novilhas aos 13 a 15 meses de idade é uma estratégia muito utilizada em países com pecuária de corte intensiva, principalmente naqueles com intenso uso de concentrados na alimentação. $\mathrm{O}$ ponto central de interesse deste sistema é o fato de existir maior eficiência biológica nas fêmeas com o primeiro parto aos dois anos quando comparadas àquelas paridas aos três ou mais anos de idade (Lesmeister et al., 1973; Nuñez Dominguez et al., 1991; Morrison et al., 1992).

No Brasil, em especial no Rio Grande do Sul, os sistemas de produção são, na maioria, a pasto, dificultando em parte o desenvolvimento precoce das novilhas. A pastagem natural dos campos gaúchos, base alimentar dos rebanhos de cria e recria no estado, é reconhecida por suas qualidades no período estival. Entretanto, diminui sua produção e reduz sua qualidade no outono e inverno, coincidindo com a fase inicial de recria das bezerras. A dificuldade é atender às exigências de crescimento em tempo hábil para a fêmea atingir a puberdade com um ano de idade.

Quando estabelecido o "sistema dois anos", o emprego de pastagens cultivadas de ciclo hiberno-primaveril no primeiro inverno pós-desmama permite atingir o peso alvo antes do primeiro serviço (Beretta \& Lobato, 1996; Pereira Netto et al., 1999). O peso alvo ao primeiro serviço para novilhas Bos taurus é de $60 \%$ e para Bos indicus, de $65 \%$ do seu peso adulto (NRC, 1996). O "sistema um ano", por sua vez, requer altas taxas de ganho de peso da desmama ao acasalamento (Lamond, 1970). Portanto, no período de outono e início do inverno, é imprescindível suplementação alimentar.

No Rio Grande do Sul, o uso de pastagens cultivadas de ciclo hiberno-primaveril na recria intensiva é indispensável do ponto de vista biológico e econômico. Entretanto, no outono e início do inverno, período de estabelecimento destas pastagens, devem ser testadas alternativas de volumosos e concentrados como suplementos para manter ganhos de peso das bezerras no início da recria e, com isto, proporcionar condições nutricionais para o adequado desenvolvimento para acasalamento de novilhas aos 13 a 15 meses de idade.

Neste sentido, este trabalho foi desenvolvido com o objetivo de avaliar o desenvolvimento corporal de bezerras Hereford e Braford após o desmame e seus efeitos na taxa de prenhez aos 13 a 15 meses de idade.

\section{Material e Métodos}

O experimento foi conduzido na Fazenda Santa Tereza, Município de Arambaré, na região fisiográfica da Encosta do Sudeste, a $156 \mathrm{~km}$ ao sul de Porto Alegre, RS. O clima da região é do tipo $\mathrm{Cfa}$, clima subtropical úmido sem estiagem, segundo a classificação de Köepen (Moreno, 1961). O solo pertence à unidade de mapeamento Pelotas, classificado como Planossolo Hidromófico Eutrófico. Estes solos são característicos de áreas de várzeas, com relevo plano a suavemente ondulado (Brasil, 1973).

No experimento, foram avaliadas bezerras de dois grupos genéticos (GG), 56 da raça Hereford e 52 Braford, todas com peso e data de nascimento conhecidos, divididas em quatro fases de avaliação da desmama (15/4/2001) até o final do período de acasalamento (31/1/2002). Na desmama, a média do peso, da condição corporal e da idade foi de $126 \mathrm{~kg}$, de 2,5 pontos e seis meses, respectivamente. A variação na idade das bezerras foi de 120 dias.

Inicialmente, as bezerras permaneceram em pastagem nativa por 45 dias, em lote único, até 1/6/2001. A partir daí foram distribuídas por GG e peso corporal em três sistemas alimentares (SA) por um período de 80 dias (1/6/2001 a 20/8/2001): CN+FA - 36 bezerras suplementadas em pastagem nativa $(\mathrm{CN})$ com farelo de arroz desengordurado (FA); SB+FA - 36 bezerras confinadas a céu aberto recebendo silagem de sorgo de baixa qualidade $(\mathrm{SB})+\mathrm{FA}$; $\mathrm{SS}+\mathrm{RC}-$ 36 bezerras confinadas a céu aberto recebendo silagem de sorgo de qualidade superior + ração comercial (RC).

O potreiro de pastagem nativa ( $25 \mathrm{ha}$ ) foi manejado com a finalidade de manter a massa de forragem inicial de $1.400 \mathrm{~kg} / \mathrm{ha}$ de matéria seca (MS). Os confinamentos a céu aberto foram em áreas de 1,5 ha.

Os concentrados foram fornecidos na proporção de $1,5 \%$ do PV nos SA. A quantidade oferecida foi reajustada a cada pesagem dos animais. No SB+FA e SS+RC, as bezerras foram alimentadas duas vezes ao dia. Os concentrados foram oferecidos misturados à silagem dentro do vagão forrageiro pela manhã, às $9 \mathrm{~h}$. Na parte da tarde, às $16 \mathrm{~h}$, os animais receberam somente a silagem, em quantidades suficientes para o consumo à vontade. No $\mathrm{CN}+\mathrm{FA}$, o concentrado foi oferecido uma vez ao dia pela parte da manhã, às $9 \mathrm{~h}$.

Ao término dos tratamentos, em 20/8/2001, as bezerras foram colocadas em pastagem de azevém (Lolium multiflorum Lam), sobresemeada em resteva de arroz em lote único. A massa de forragem média foi de $1.500 \mathrm{~kg} / \mathrm{ha}$ de MS, conforme Mott (1984), permanecendo nesta média até o início do acasalamento (1/12/2001).

No período de acasalamento, as novilhas foram mantidas em pastagem nativa, com massa de forragem média de $1.800 \mathrm{~kg} / \mathrm{ha} \mathrm{de} \mathrm{MS} \mathrm{(Maraschin} \mathrm{et} \mathrm{al.,} \mathrm{1997).} \mathrm{O} \mathrm{acasalamento}$ teve duração de 60 dias (1/12/2001 a 1/2/2002) com a utilização permanente de $3 \%$ de touros Hereford, todos com 
DEP (Diferença Esperada na Progênie) negativa somente para peso ao nascimento. O diagnóstico de prenhez foi realizado via palpação transretal no dia 1/6/2002.

A massa de forragem em todas as pastagens foi medida com 20 cortes junto ao solo por potreiro, representativos da média, no início e final de cada período de pastejo, utilizando-se um quadro com área de $0,25 \mathrm{~cm}^{2}$. Posteriormente, as amostras foram secas em estufa a $65^{\circ} \mathrm{C}$ e calculadas em $\mathrm{kg} / \mathrm{ha}$ de MS.

As amostras coletadas das pastagens, silagens e concentrados foram encaminhadas para análises bromatológicas, determinando-se os teores de proteína bruta (PB), nutrientes digestíveis totais (NDT) e fibra detergente neutro (FDN), de acordo com a metodologia descrita pela AOAC (1975).

Da desmama ao início dos SA, a pastagem nativa apresentou teores de PB e NDT de 6,2 e 55,5\%, respectivamente. No período correspondente aos SA, o CN apresentou teores de PB de 6,7\%, NDT de 57,0\% e FDN de 70\%; a SB, $4,7 \%$ de PB, $55,0 \%$ de NDT e 75,0\% de FDN; a SS, 5, 5\% de PB, $62,0 \%$ de NDT e $65,0 \%$ de FDN; o FA, $13,9 \%$ de PB e $65,0 \%$ de NDT; a RC, $13,9 \%$ de PB e 73,0\% de NDT.

No período posterior aos SA, a pastagem de azevém teve, em média, $12,1 \%$ de PB e $70,0 \%$ de NDT. Durante o período de acasalamento, a pastagem nativa teve $9,5 \%$ de PB e $62,0 \%$ de NDT.

As bezerras foram pesadas com jejum de sólidos e líquidos de 12 horas ao início e final de cada fase de avaliação e em períodos intermediários de 28 dias. O ganho médio de peso diário foi calculado pela diferença do peso final e inicial do período, dividido pelo número de dias do mesmo. As médias obtidas foram ponderadas conforme o número de dias de cada período.

A avaliação do escore de condição corporal (ECC) foi realizada ao início e término de cada período de avaliação. Os critérios utilizados foram adaptados conforme classificação proposta por Lowman et al. (1973), cuja escala varia de 1 (muito magra) a 5 (muito gorda).

Odelineamento experimental foi inteiramente casualizado com parcelas subdivididas no tempo, em um fatorial $2 \times 3$, sendo as repetições formadas conforme o SA e o GG dos animais. O modelo matemático referente aos parâmetros analisados foi:

$$
\mathrm{Y}_{\mathrm{ij}}=\mu+\mathrm{GG}_{\mathrm{i}}+\mathrm{SA}_{\mathrm{j}}+(\mathrm{GG} * \mathrm{SA})_{\mathrm{ij}}+\sum_{\mathrm{ij}}
$$

em que $\mathrm{Y}_{\mathrm{ij}}=$ variáveis dependentes; $\mu=$ média de todas as observações; $\mathrm{GG}_{\mathrm{i}}$ = efeito do i-ésimo grupo genético; $\mathrm{SA}_{\mathrm{j}}=$ efeito do j-ésimo sistema alimentar; $(\mathrm{GG} * \mathrm{SA})_{\mathrm{ij}}=$ efeito de interação i-ésimo grupo genético $\times \mathrm{j}$-ésimo sistema alimentar; $\Sigma_{\mathrm{ij}}=$ erro residual.

Os dados coletados foram submetidos à análise de variância e teste F. Quando detectadas diferenças entre GG,
SA e ou interação GG*AS, foi realizada comparação de médias pelo teste de Tuckey. As análises foram efetuadas com o auxílio do procedimento "General Linear Model" (GLM). Os dados referentes à taxa de prenhez foram analisados pelo método do qui-quadrado. O programa estatístico utilizado foi o SAS versão 6.08 (SAS, 1997). O nível máximo de significância adotado foi de 5\%.

\section{Resultados e Discussão}

Da desmama (15/4/2001) ao início dos SA (1/6/2001), as bezerras tiveram, em pastagem nativa, ganho de peso praticamente nulo $(0,050 \mathrm{~kg} / \mathrm{dia})$, provavelmente em função do estresse pós-desmama e da baixa defesa imunológica desta categoria, associados à qualidade limitante da pastagem nativa do período. A forragem era composta, em grande parte, por material senescente proveniente dos meses de verão e apresentou $6,2 \%$ de PB e 55,5\% de NDT. Com a mesma categoria animal, Quintans et al. (1993) observaram perda média de peso de $33 \mathrm{~kg} /$ animal da desmama ao início da suplementação (abril a junho).

Os animais do SS+RC tiveram GMD superior $(0,480 \mathrm{~kg})$ ao $\mathrm{SB}+\mathrm{FA}(0,252 \mathrm{~kg})$ e ambos sobre o $\mathrm{CN}+\mathrm{FA}(0,174 \mathrm{~kg})$ (Tabela 1$)$.

O menor GMD verificado no $\mathrm{CN}+\mathrm{FA}$ esteve relacionado à baixa massa de forragem, média de $1.330 \mathrm{~kg} / \mathrm{ha}$ de $\mathrm{MS}$, associada à qualidade limitante da pastagem nativa neste período. A menor massa de forragem pode ter determinado menor efeito da suplementação, pois ganhos considerados satisfatórios em animais sob suplementação em pastagem nativa são obtidos somente quando a massa de forragem é superior a $1.800 \mathrm{~kg} / \mathrm{ha} \mathrm{MS} \mathrm{(Manzano} \mathrm{et} \mathrm{al.,} \mathrm{1993).} \mathrm{Quando} \mathrm{a}$ quantidade de forragem é restrita, a suplementação concentrada pode aumentar a digestibilidade total da matéria orgânica consumida e o desempenho animal (Prache et al., 1990).

Tabela 1 - Peso corporal inicial ( $\mathrm{PCl}, \mathrm{kg}$ ) e final (PCF, kg) e ganhos de peso médios diários (GMD, kg) das bezerras submetidas a três sistemas alimentares no outono-inverno pós-desmama

\begin{tabular}{lccc}
\hline Sistema alimentar & PCI & PCF & GMD \\
\hline CN+FA & 126 & $140 \mathrm{~b}$ & $0,174 \mathrm{c}$ \\
SB+FA & 131 & $151 \mathrm{~b}$ & $0,252 \mathrm{~b}$ \\
SS+RC & 129 & $167 \mathrm{a}$ & $0,480 \mathrm{a}$ \\
Média & 128 & 153 & 0,302 \\
EPM & $\pm 22,9$ & $\pm 29,5$ & $\pm 0,192$
\end{tabular}

a,b,c, - na mesma coluna, diferem $(P<0,05)$.

Período - 01/06/01-20/08/01.

$\mathrm{CN}+\mathrm{FA}=$ pastagem nativa + farelo de arroz desengordurado; $\mathrm{SB}+\mathrm{FA}=$ silagem de sorgo de baixa qualidade + farelo de arroz desengordurado SS+RC - silagem de sorgo de qualidade superior + ração comercial. 
Dois fatores afetam a ingestão de nutrientes quando bovinos em pastejo receberam dietas suplementadas com concentrado: a taxa de substituição da forragem pelo concentrado e a depressão da digestão da fibra. Em pastagem de baixa qualidade e em quantidades limitantes, a depressão na digestão da fibra afeta mais a ingestão de nutrientes, interferindo na resposta animal (Rearte \& Pieroni, 2001).

O maior GMD verificado no sistema $\mathrm{SB}+\mathrm{FA}$ em relação ao $\mathrm{CN}+\mathrm{FA}$ foi influenciado pela maior quantidade de volumoso prontamente disponível aos animais, embora a qualidade da silagem neste tratamento tenha sido inferior à da pastagem nativa. Quando agregada maior qualidade na dieta e não havendo limitação na quantidade de alimento oferecida ( $\mathrm{SS}+\mathrm{RC})$, as bezerras obtiveram GMD superior ao verificado nos demais SA.

A interação qualitativa e quantitativa foi determinante para o maior consumo e GMD das bezerras $\mathrm{SS}+\mathrm{RC}$, visto que as exigências nutricionais desta categoria animal para ganhos de $0,300 \mathrm{~kg} / \mathrm{dia}$ são de $12 \%$ de PB e $60 \%$ de NDT e um consumo de $2,0 \%$ do PV (NRC, 1984).

Os ganhos de peso obtidos neste trabalho foram inferiores aos verificados por Beretta \& Lobato (1998), os quais observaram GMD de 0,744 kg nos animais confinados, superior aos $0,380 \mathrm{~kg}$ dos animais em pastejo. Rocha \& Lobato (2002a), por sua vez, não evidenciaram essas diferenças entre o sistema de suplementação a campo, confinamento e pastagem cultivada de azevém.

Os GMD alcançados, com exceção do SS+RC, foram inferiores aos almejados para o sucesso do "sistema um ano", o qual tem alta relação com ganho de peso e eficiência de crescimento pós-desmama (Varner et al., 1977; Dziuk \& Bellows, 1983).

$\mathrm{O}$ peso das novilhas ao final do período dos SA de $167 \mathrm{~kg}$ no SS+RC foi superior ao SB+FA e $\mathrm{CN}+\mathrm{FA}, 151 \mathrm{e}$ $140 \mathrm{~kg}$, respectivamente. De acordo com Short \& Bellows (1971) e Ferrel (1982), as diferentes taxas de ganhos, associadas a diferentes sistemas alimentares, têm influência significativa na deposição em tecidos moles, determinando diferenças na condição e peso corporais.

Na pastagem de azevém, após o período de suplementação, não existiu diferença no GMD, 0,436 kg (Tabela 2). Vários trabalhos conduzidos sob pastejo contínuo em aveia (Avena strigosa Schreb) e azevém em áreas com maior fertilidade e oferta de forragem demonstram que o GMD para esta categoria animal (entre 0,600 e 0,900 kg) também é dependente do manejo dos animais pré-pastejo e da duração do período total de pastejo (Roso \& Restle, 2000; Frizzo et al., 2003).

Em pastagens sobresemeadas em grandes áreas de resteva de arroz, fatores como dificuldades de drenagem e implantação do azevém podem impossibilitar o adequado
Tabela 2 - Ganho de peso médio diário (GMD, kg) das novilhas em lote único sobre pastagem de azevém após o período de suplementação e em pastagem nativa durante o acasalamento

\begin{tabular}{lcc}
\hline Sistema alimentar & \multicolumn{2}{c}{ Período } \\
\cline { 2 - 3 } & Pós-suplementação & $\begin{array}{c}\text { Acasalamento } \\
\text { 20/08/01-30/11/01 }\end{array}$ \\
& 0,462 & 0,504 \\
CN+FA & 0,441 & 0,547 \\
SB+FA & 0,405 & 0,507 \\
SS+RC & 0,436 & 0,519 \\
Média & $\pm 0,118$ & $\pm 0,118$ \\
EPM &
\end{tabular}

$\mathrm{P}>0,05$.

$\mathrm{CN}+\mathrm{FA}=$ pastagem nativa + farelo de arroz desengordurado; $\mathrm{SB}+\mathrm{FA}=$ silagem de sorgo de baixa qualidade + farelo de arroz desengordurado; SS+RC - silagem de sorgo de qualidade superior + ração comercial.

manejo. Neste trabalho, a massa de forragem média de $1.050 \mathrm{~kg} / \mathrm{ha}$ de MS ficou aquém dos $1.500 \mathrm{~kg} / \mathrm{ha}$ de MS preconizados para o máximo desempenho animal. Em pastagem manejada com massa de forragem semelhante, Rocha et al. (2003) também verificaram ganhos de peso inferiores a $0,500 \mathrm{~kg} / \mathrm{dia}$ com a mesma categoria animal.

No período total da recria, as diferenças em ganho de peso existentes durante a suplementação de outono-inverno mantiveram-se. Estes ganhos representaram crescimento relativo ao peso de $126 \mathrm{~kg}$ da desmama de 50, 56 e $67 \%$ nos sistemas $\mathrm{CN}+\mathrm{FA}, \mathrm{SB}+\mathrm{FA}$ e $\mathrm{SS}+\mathrm{RC}$, respectivamente, em um período de recria de 229 dias até o início do acasalamento.

A taxa de crescimento durante a recria está relacionada ao peso à desmama principalmente quando os animais são submetidos a elevado nível alimentar durante a recria (Pilau \& Lobato, 2006). Altas taxas de crescimento relativo são observadas em animais com baixos pesos à desmama que experimentam altas taxas de ganho no pós-desmame. Esta resposta foi verificada por Beretta \& Lobato (1998) com bezerras de peso à desmama de $120 \mathrm{~kg}$, obtendo baixa resposta reprodutiva aos 14 a 15 meses de idade.

Para ser acasalada aos 14 meses de idade entre a desmama e o acasalamento, a novilha deve realizar ganho correspondente a $25 \%$ do seu peso adulto, pressupondo que esse animal tenha cerca de $40 \%$ deste peso por ocasião da desmama e deva atingir $65 \%$ no acasalamento (Rocha \& Lobato, 2002a). Nesta pesquisa, considerando o peso adulto de $460 \mathrm{~kg}$ para as vacas de cria do rebanho em estudo, na desmama as bezerras tinham apenas $27 \%$ do seu peso adulto, tendo o ganho de peso da recria correspondido a aproximadamente $15 \%$ do peso adulto. A probabilidade de as bezerras atingirem a maturidade sexual antes do período de acasalamento aos 13 a 15 meses de idade é influenciada pelo somatório de fatores determinantes do peso ao desmame e do ganho de peso pós-desmame 
(Bergmann \& Hohenboken, 1992), os quais foram insuficientes para elevado desempenho reprodutivo neste trabalho.

Durante o período de acasalamento, não foram verificados efeitos dos sistemas alimentares no GMD. Considerando-se GMD de 0,519 kg satisfatório, infere-se que esta variável durante o acasalamento não proporcionou aumento imediato no desempenho reprodutivo, como observado por Rocha \& Lobato (2002b), com GMD semelhante. Seus efeitos tornar-se-ão importantes para o desenvolvimento da novilha no período inicial da gestação.

As diferenças de peso corporal identificadas ao final dos SA foram mantidas até 31/1/2002, final do período de acasalamento (Tabela 3 ).

O peso corporal proposto pelo NRC (1996) para manifestação da puberdade na novilha é de 60 e $65 \%$ do peso adulto para taurinas e zebuínas, respectivamente. Os três SA, com 42, 44, 46\% no CN+FA, SB+FA e SS+RC, respectivamente, ficaram abaixo dos percentuais preconizados ao início do acasalamento. Conforme Byerley et al. (1987), as novilhas devem atingir peso corporal para manifestação da puberdade antes do início do acasalamento, sendo os níveis de concepção superiores nas novilhas que já tenham expressado três ciclos estrais no início do período reprodutivo, se comparadas àquelas acasaladas no cio púbere. Isto porque a fertilidade do terceiro cio é $21 \%$ superior à do cio púbere.

A condição corporal das novilhas $\mathrm{SB}+\mathrm{FA}$ e $\mathrm{SS}+\mathrm{RC}$ foi superior ao início do período de acasalamento em relação às do $\mathrm{CN}+\mathrm{FA}, 3,3$ e 3,4 contra 3,0, respectivamente, mantendo-se superior até o final do período. Entretanto, os escores observados são insuficientes para alta resposta reprodutiva aos 13/15 meses de idade. A fêmea jovem não pode ovular pela primeira vez até acumular uma quantidade crítica de gordura em relação a sua massa corporal como um princípio de sobrevivência e preservação das espécies representadas pelas exigências da gestação e lactação (Bronson \& Manning, 1991).
Segundo Wiltbank et al. (1985), as novilhas devem atingir 65 a $70 \%$ do seu peso adulto na maturidade sexual, além de estar em condição corporal moderada à alta no início de sua primeira estação de acasalamento. Portanto, grande parte das novilhas não tinha, ao início do período reprodutivo, $\mathrm{PV}$ e CC para a concepção.

Na taxa de prenhez (TP) não foram verificadas diferenças entre os SA, média de 17\%. As novilhas SS+RC, mesmo recebendo nível alimentar superior no outono/inverno, com maiores ganhos e maior peso médio ao início do acasalamento, não os traduziu em maior TP em relação aos demais SA.

A baixa TP dos três SA foi reflexo da combinação de três fatores principais: baixo peso à desmama e ao início dos tratamentos alimentares (Marshall, 1991); GMD abaixo do almejado na recria (Short \& Bellows, 1971; Lehman et al., 1993); e GMD insuficiente até o final do acasalamento para que se alcançassem o peso alvo (Lamond, 1970).

No Brasil e em especial no RS, tem-se observado em alguns trabalhos a influência destes fatores sobre a resposta reprodutiva aos 13/15 meses de idade. Taxas de prenhez inferiores a $50 \%$ foram observadas com baixo peso à desmama, independentemente dos ganhos obtidos na recria (Freitas et al., 2003; Pilau et al., 2004). Taxas de prenhez entre $50 \mathrm{e} 70 \%$ foram alcançadas com peso à desmama adequado ao tipo animal utilizado e com ganhos moderados na recria (Rocha \& Lobato, 2002b). Taxas de prenhez superiores a $85 \%$ foram obtidas com peso à desmama adequado ao tipo animal e altos ganhos durante a recria (Pilau et al., 2005).

O peso médio das novilhas Hereford ao início do acasalamento foi de $186 \mathrm{~kg}$, correspondendo a $41 \%$ do peso adulto do rebanho Hereford ( $450 \mathrm{~kg}$ ). Nas novilhas Braford o peso médio foi de $211 \mathrm{~kg}, 44 \%$ do peso adulto do rebanho Braford ( $480 \mathrm{~kg}$ ) neste estudo (Tabela 4). Ambos estão bem distantes do proposto pelo NRC (1996), de 60 e $65 \%$ do peso adulto. Em trabalho com bezerras de $143 \mathrm{~kg}$ e 150 dias de idade ao desmame, Moraes \& Lobato (1993) evidenciaram

Tabela 3 - Peso e condição corporais ao início e final do acasalamento e taxa de prenhez de novilhas submetidas a três sistemas alimentares no outono-inverno pós-desmame

\begin{tabular}{lcccccc}
\hline Sistema alimentar & \multicolumn{2}{c}{ Peso corporal $(\mathrm{kg})$} & & Condição corporal $(1-5)$ & \multirow{2}{*}{ Prenhez $(\%)$} \\
\cline { 2 - 3 } & Inicial & Final & & Inicial & Final \\
\hline CN+FA & $189 \mathrm{~b}$ & $219 \mathrm{~b}$ & & $3,0 \mathrm{~b}$ & $3,2 \mathrm{~b}$ & 11 \\
SB+FA & $197 \mathrm{ab}$ & $230 \mathrm{ab}$ & & $3,3 \mathrm{a}$ & $3,4 \mathrm{a}$ & 14 \\
SS+FA & $210 \mathrm{a}$ & $240 \mathrm{a}$ & & $3,4 \mathrm{a}$ & $3,5 \mathrm{a}$ & \\
Média & 199 & 230 & 3,2 & 3,4 & 17 \\
EPM & $\pm 32,9$ & $\pm 32,7$ & & $\pm 0,5$ & $\pm 0,5$ \\
\hline
\end{tabular}

Acasalamento - 01/12/01 a 31/01/02.

$a, b,-$ na mesma coluna, diferem $(P<0,05)$.

$\mathrm{CN}+\mathrm{FA}=$ pastagem nativa + farelo de arroz desengordurado; $\mathrm{SB}+\mathrm{FA}=$ silagem de sorgo de baixa qualidade + farelo de arroz desengordurado; $\mathrm{SS}+\mathrm{RC}$ - silagem de sorgo de qualidade superior + ração comercial. 
Tabela 4 - Peso e condição corporais ao início e final do acasalamento e taxa de prenhez aos 13/15 meses de idade de novilhas de diferentes grupos genéticos

\begin{tabular}{|c|c|c|c|c|c|}
\hline \multirow[t]{2}{*}{ Grupo genético } & \multicolumn{2}{|c|}{ Peso corporal $(\mathrm{kg})$} & \multicolumn{2}{|c|}{ Condição corporal (1-5) } & \multirow[t]{2}{*}{ Prenhez (\%) } \\
\hline & Inicial & Final & Inicial & Final & \\
\hline Hereford & 186 & 217 & 3,0 & 3,1 & 4 \\
\hline Braford & $211^{*}$ & $243^{*}$ & $3,5^{*}$ & $3,6^{*}$ & $31 * *$ \\
\hline Média & 199 & 230 & 3,3 & 3,4 & 17 \\
\hline EPM & $\pm 32,9$ & $\pm 32,7$ & $\pm 0,5$ & $\pm 0,5$ & \\
\hline
\end{tabular}

Acasalamento - 1/12/01 a 31/1/02.

* - na mesma coluna, diferem $(P<0,05)$.

** - na mesma coluna, diferem $(P<0,01)$

$\mathrm{CN}+\mathrm{FA}=$ pastagem nativa + farelo de arroz desengordurado; $\mathrm{SB}+\mathrm{FA}=$ silagem de sorgo de baixa qualidade + farelo de arroz desengordurado; $\mathrm{SS}+\mathrm{RC}-\mathrm{silagem}$ de sorgo de qualidade superior + ração comercial.

ser possível alcançar peso para primeiro acasalamento aos 13/15 meses, desde que na recria se obtenham elevadas taxas de ganho de peso. Os autores observaram peso ajustado aos 12 meses de idade de 260 e $269 \mathrm{~kg}$ para novilhas Hereford e Braford, respectivamente.

Foram verificadas diferenças entre os dois grupos raciais avaliados para taxa de prenhez. As novilhas Braford (31\%) apresentaram TP superior às Hereford (4\%); as Braford foram sempre mais pesadas e de maior condição corporal.

Dados compilados por Cundiff et al. (1993) e Gregory et al. (1993) de vários experimentos demonstraram que a maior idade à puberdade está sempre associada ao maior percentual de sangue zebuíno da novilha. Neste estudo a maior TP das novilhas Braford pode estar ligada aos efeitos da heterose. Quando existe cruzamento com Bos indicus, ocorre melhor adaptação dos animais a níveis nutricionais limitantes e, conseqüentemente, melhor resposta produtiva.

Exceto para peso ao nascer, as novilhas que conceberam e as não-gestantes diferiram em relação ao peso corporal, condição corporal e GMD ao desmame, no início e final dos tratamentos e do acasalamento (Tabela 5).

$\mathrm{O}$ peso médio à desmama das bezerras que ficaram prenhes foi $38 \mathrm{~kg}$ superior à média das não-gestantes. Corroborando este resultado, Patterson et al. (1992) verificaram que, em sistemas pecuários intensivos, o crescimento pré-desmama exerce maior influência na puberdade de novilhas de corte que as taxas de crescimento pós-desmama. A amplitude de peso à desmama entre as novilhas prenhes foi de 143 a $182 \mathrm{~kg}$, sendo que $66 \%$ destas novilhas pesavam mais de $150 \mathrm{~kg}$. Portanto, o peso à desmama deve ser considerado como fator determinante para a tomada de decisão em relação à idade de acasalamento mais apropriada a ser utilizada.

A diferença de peso entre as novilhas que ficaram prenhes e as não-gestantes aumentou para $56 \mathrm{~kg}$ ao final dos SA, reflexo direto das maiores taxas de ganho de peso neste período, 0,450 versus $0,270 \mathrm{~kg} /$ dia, respectivamente.
Tabela 5 - Desenvolvimento das novilhas gestantes e nãogestantes em relação ao peso corporal, à condição corporal, idade ao início do acasalamento e ao ganho médio diário até os 13/15 meses de idade

\begin{tabular}{lccc}
\hline Item & Gestante & Não-gestante & EPM \\
\hline Peso (kg) & & & \\
Nascimento & 32 & 32 & $\pm 2,7$ \\
Desmama & 158 & $120 * *$ & $\pm 21,7$ \\
Início dos sistemas alimentares & 163 & $122 * *$ & $\pm 22,8$ \\
Início da pastagem azevém & 199 & $143 * *$ & $\pm 29,4$ \\
Início do acasalamento & 251 & $188 * *$ & $\pm 32,9$ \\
Final do acasalamento & 279 & $219 * *$ & $\pm 32,7$
\end{tabular}

Condição corporal (1-5)

Início dos sistemas alimentares $3,2 \quad 2,8 * * \quad \pm 1,5$

Início da pastagem azevém $\quad 3,7 \quad 2,7 * * \pm 1,3$

Início do acasalamento $\quad 3,9 \quad 3,1 * * \quad \pm 0,5$

Final do acasalamento $\quad 4,2 \quad 3,2 * * \pm 0,5$

Idade ao acasalamento (dias) $413 \quad 387 * * \quad \pm 27,8$

GMD $(\mathrm{kg})$

Nos sistemas alimentares $\quad 0,450 \quad 0,270 * * \quad \pm 0,192$

Da desmama ao acasalamento $0,413 \quad 0,379 * * \quad \pm 0,175$

** na mesma linha, $P<0,01$.

Estes resultados concordam com a inferência de Short \& Bellows (1971) e Martin et al. (1992) acerca da importância dos sistemas alimentares no período pós-desmama e da capacidade genética para ganho de peso de cada animal para o sucesso reprodutivo aos 13/15 meses de idade.

O GMD superior das novilhas que ficaram prenhes, durante o período entre a desmama e o acasalamento, confirma a hipótese de Short \& Bellows (1971) de que baixas taxas de ganho de peso na recria retardam a puberdade de novilhas para o "sistema um ano".

Como resultado de maior peso médio à desmama e de GMD superiores da desmama ao acasalamento, foram verificadas diferenças no PIA, $251 \mathrm{~kg}$ para as prenhes versus $188 \mathrm{~kg}$ das não-gestantes. No trabalho de Ellis (1974), a relação entre o peso ao início do acasalamento e 
a taxa de parição foi linear dos 175 aos $265 \mathrm{~kg}$. Nesta amplitude de peso, a taxa de prenhez aumentou em $7 \%$ para cada $10 \mathrm{~kg}$ de peso corporal, tendo o autor proposto o peso alvo em torno de $270 \mathrm{~kg}$ para taxa de prenhez de aproximadamente $80 \%$

A condição corporal das prenhes foi sempre superior à das não-gestantes. Esta diferença foi de 0,89 ponto no início do acasalamento e de 1,02 ponto ao final do mesmo. Estes resultados foram semelhantes aos obtidos por Semmelmann et al. (2001) e Rocha \& Lobato (2002b).

As novilhas gestantes foram mais velhas que as nãogestantes $(413 \times 387$ dias), concordando com os trabalhos de Bergmann \& Hohenboken (1992), Semmelmann et al. (2001) e Rocha \& Lobato (2002b). Burfening et al. (1979), usando como critério a idade, observaram 28,55 e $83 \%$ de manifestação de puberdade aos 12,13 e 14 meses de idade.

\section{Conclusões}

Maior desempenho durante a suplementação alimentar no outono-inverno não se traduz em maior desempenho reprodutivo em novilhas acasaladas aos 13/15 meses de idade, quando se dispõe de baixo peso à desmama e baixos ganhos de peso após a suplementação.

Em níveis de desenvolvimento moderados na recria, as novilhas Braford apresentam maior ganho de peso em relação às Hereford e, conseqüentemente, maior taxa de prenhez aos 13/15 meses de idade.

As novilhas que concebem aos 13/15 meses de idade, quando se tem baixo peso médio na desmama, são mais pesadas e apresentam maiores taxas de ganho de peso e condição corporal até o final do período de acasalamento.

\section{Literatura Citada}

ASSOCIATION OF OFFICIAL ANALITICAL CHEMISTS - AOAC. Official methods of analysis. 12.ed. Washington, D.C.: 1975. $1094 \mathrm{p}$.

BERETTA, V.; LOBATO, J.F.P.; MIELITZ NETO, C.G.A. Produtividade e eficiência biológica de sistemas pecuários diferindo na idade das novilhas ao primeiro parto e na taxa de natalidade do rebanho no Rio Grande do Sul. Revista Brasileira de Zootecnia, v.30, n.4, p.1278-1286, 2001

BERETTA, V.; LOBATO, J.F.P. Sistema "um ano" de produção de carne: avaliação de estratégias alternativas de alimentação hibernal de novilhas de reposição. Revista Brasileira de Zootecnia, v.27, n.1, p.157-163, 1998.

BERETTA, V.; LOBATO, J.F.P. Efeitos da ordem de utilização de pastagens melhoradas no ganho de peso e desempenho reprodutivo de bezerras de corte. Revista Brasileira de Zootecnia, v.25, n.1, p.46-57, 1996

BERGMANN, J.A.G.; HOHENBOKEN, W.D. Prediction of fertility on calf hood traits of Angus and Simenthal heifers. Journal of Animal Science, v.70, n.9, p.2611-2621, 1992
BRASIL. Ministério da Agricultura. Departamento Nacional de Pesquisa Agropecuária. Divisão de Pesquisa Pedológica. Levantamento de reconhecimento de solos do Estado do Rio Grande do Sul. Recife: 1973. 431p. (Boletim Técnico, 30). BRONSON, F.H.; MANNING, J.M. The energetic regulation of ovulation: a realistic role of body fat. Biology Reprodution, v.44, n.6, p.945-950, 1991

BURFENING, P.J.; KRESS, D.D.; ANDERSON, D.C. et. al. Heterosis among closed lines of hereford cattle. II. Postweaning growth and puberty in heifers. Journal of Animal Science, v.49, n. 4, p. $598,1979$.

BYERLEY, D.J.; STAIGMILLER, R.B.; BERLRDINELLI, J.G. et al. Pregnancy rates of beef heifers bred either on puberal or third estrus. Journal of Animal Science, v.65, n.3, p.645$650,1987$.

CUNDIFF, L.; SZABO, F.; GREGORY, K. et. al. Breed comparisons from the MARC-ARS-USDA germoplasm evaluation program. In: MEETING OF BEEF IMPROVEMENT FEDERATION, 25. 1993, Asheville. Proceedings... Asheville: 1993. 17p.

DZIUK, P.J.; BELLOWS, R.A. Management of reproduction of beef cattle, sheep and pigs. Journal of Animal Science, v.57, n.2, p.355-377, 1983 .

ELLIS, R.W. The relationship between percentage calving and weight at joining in early Hereford heifers. In: AUSTRALIAN SOCIETY OF ANIMAL PRODUCTION, 10., 1974, Sidney. Proceedings... Sidney: Australian Society of Animal Production, 1974. p.55.

FERREL, C.L. Effects on post weaning rate of gain on onset of puberty and produtive performance of heifers of different breeds. Journal of Animal Science, v.55, n.6, p.1272-1284, 1982.

FREITAS, S.G.; LOBATO, J.F.P.; TAROUCO, A.K. et al. Desempenho reprodutivo e produtivo de novilhas de corte aos dois anos de idade submetidas a diferentes alternativas de utilização. In: REUNIÃO ANUAL DA SOCIEDADE BRASILEIRA DE ZOOTECNIA, 40., 2003, Santa Maria. Anais... Santa Maria: Sociedade Brasileira de Zootecnia, 2003. (CD-ROM).

FRISCH, R.E. Body fat, puberty and fertility. Biology Review, v.59, n.2, p.161-168, 1984

FRIZZO, A.; ROCHA, M.G.; RESTLE, J. Suplementação energética na recria de bezerras de corte mantidas em pastagem de inverno. Revista Brasileira de Zootecnia, v.32, n.3, p.643-352, 2003.

GREGORY, K.; CUNDIFF, L.; KOCH, R. et. al. Germoplasm utilization in beef catle: beef research. Clay Center: U.S Meat Animal Research Center, 1993. p.7-19. (Beef Research Program Report).

LAMOND, D.R. The inffluence of undernutrition on reproduction in the cow. Animal Breeding Abstract, v.38, p.359-372, 1970

LEHMAN, F.D.; ENGELKEN, T.J.; RANDALL, L.D. et al. A logical method for comparing beef heifer development strategies. Veterinary Medicine, p.1094-1101, 1993.

LESMEISTER, J.L.; BURFENING, P.J.; BLACKWELL, R.L. Date of first calving in beef cows and subsequent calf production. Journal of Animal Science, v.36, n.1, p.1-6, 1973.

LOWMAN, B.G.; SCOTT, N.; SOMERVILLE, S. Condition scoring beef cattle. Edinburgh: East of Scotland College of Agriculture, 1973. 8p.

MANZANO, A.; BARBOSA, P.F.; ALENCAR, M.M. et. al. Influência da suplementação sobre o peso à puberdade e as idades à puberdade aos trezentos quilos de fêmeas da raça Canchim. Revista Brasileira de Zootecnia, v.22, n.2, p.341-349, 1993.

MARASCHIN, G.E.; MOOJEN, E.L.; ESCOTEGUY, C.M.D. et al Native pasture, forage on offer and animal response In: INTERNATIONAL GRASSLAND CONGRESS, 18., 1997, Saskatoon. Proceedings... Saskatoon: 1997. v.2, p.288.

MARSHALL, T.T.; MINQUIANG, W.; FREKING, B.A. Relative calving date of first calf heifers as related to production efficiency and subsequent reproductive performance. Journal of Animal Science, v.68, n.4, p.1812, 1991. 
MARTIN, L.C.; BRINKS, J.S.; BOURDON, R.M. et. al. Genetic effects on beef heifers puberty and subsquent reproduction. Journal of Animal Science, v.70, n.1, p.4006-4017, 1992.

MORAES, A.A.S.; LOBATO, J.F.P. Efeito de duas idades de desmame no desenvolvimento de bezerros de corte. Revista Brasileira de Zootecnia, v.22, n.6, p.885-892, 1993.

Moreno, J.A. Clima do Rio Grande do Sul. Porto Alegre: Secretaria da Agricultura, 1961. 41p.

MORRISON, D.G.; FEAZEL, J.I.; BAGLEY, C.P. et. al. Postweaning growth and reproduction of beef heifers exposed to calve at 24 and 36 months of age in spring and fall season. Journal of Animal Science, v.70, n.3, p.622-630, 1992.

MOTT, G.O. Relationship of available forage and animal performance in tropical grazing systems. In: FORAGE GRASSLAND CONFERENCE, 1984, Houston. Proceedings... Lexington: American Forage and Grassland Council, 1984. p.373-377.

NATIONAL RESEARCH COUNCIL - NRC. Nutrient requirements of beef cattle. Washington: National Academy Press, 1996. $242 \mathrm{p}$.

NATIONAL RESEARCH CONCIL - NRC. Nutrient requirement of beef cattle. 6.ed. Washington: National Academy Press, 1984. 90 p.

NUÑEZ-DOMINGUEZ, R.; CUNDIFF, L.V.; DICKERSON, G.E. et al. Lifetime production of beef heifers calving first at two vs. three years of age. Journal of Animal Science, v.69, n.9, p.3467-3479, 1991.

PATERSON, D.J.; PERRY, R.C.; KIRAKOFE, G.H. et. al. Managements considerations in heifers development and puberty. Journal of Animal Science, v.70, n.12, p.40184035, 1992.

PEREIRA NETO, O.; LOBATO, J.F.P.; SIMEONE, A. Sistema de pastejo rotativo ponta e rapador para bezerras de corte. 1. Desempenho corporal. Revista Brasileira de Zootecnia, v.28, n.1, p.137-142, 1999

PILAU, A.; LOBATO, J.F.P. Recria de bezerras com suplementação no outono e pastagem cultivada no inverno. Revista Brasileira de Zootecnia, v.35, n.6, p.2388-2396, 2006.

PILAU, A.; LOBATO, J.F.P; SANTOS, D.T. et al. Recria e acasalamento de novilhas de corte aos 14/15 meses de idade em sistemas a pasto. In: REUNIÃO ANUAL DA SOCIEDADE BRASILEIRA DE ZOOTECNIA, 42., 2005, Goiânia. Anais... Goiânia: Sociedade Brasileira de Zootecnia, 2005. (CD-ROM).

PILAU, A.; LOBATO, J.F.P.; SANTOS, D.T. et al. Efeito de rebanho e suplementação energética sobre o desempenho reprodutivo de novilhas de corte acasaladas aos 14 meses de idade. In: REUNIÃO ANUAL DA SOCIEDADE BRASILEIRA DE ZOoteCniA, 41., 2004, Campo Grande. Anais... Campo Grande: Sociedade Brasileira de Zootecnia, 2004. (CD-ROM).

QUINTANS, G.; VAZ MARTINS, D.; CARRIQUIRY, E. Effecto de la suplementacion ivernal sobre el comportamiento de terneras. In: Campo Natural. Estrategia ivernal, manejo y suplementacion. Treinta y Tres: Instituto Nacional de Investigación Agropecuaria, 1993. p.35.

REARTE, D.H.; PIERONI, G.A. Supplementation of temperate pastures. In: INTERNATIONAL GRASSLAND CONGRESS, 19. 2001, São Pedro. Preceedings... São Pedro: 2001. p.679-689.

ROCHA, M.G.; RESTLE, J.; PILAU, A. et al. Produção animal e retorno econômico da suplementação em pastagem de aveia e azevém. Ciência Rural, v.33, n.3, p.85-93, 2003.

ROCHA, M.G.; LOBATO, J.F.P. Sistemas de alimentação pósdesmama de bezerras de corte para acasalamento com 14/15 meses de idade. Revista Brasileira de Zootecnia, v.31, n.4, p.1814-1822, 2002a.

ROCHA, M.G.; LOBATO, J.F.P. Avaliação do desempenho reprodutivo de novilhas de corte primíparas aos dois anos de idade. Revista Brasileira de Zootecnia, v.31, n.3, p.13881395, 2002b.

ROSO, C.; RESTLE, J. Aveia preta preta, triticale e centeio em mistura com azevém. 2. Produtividade animal e retorno econômico. Revista Brasileira de Zootecnia, v.29, n.1, p.8593, 2000 .

STATISTICAL ANALYSIS SYSTEM - SAS. SAS/STAT user's guide: statistics. 4.ed. Version 6, Cary: SAS Institute, 1997. v. $2,943 p$.

SEMMELMANN, C.E.N.; LOBATO, J.F.P.; ROCHA, M.G. Efeito de sistemas de alimentação no ganho de peso e desempenho reprodutivo de novilhas Nelore acasaladas aos 17-18 meses. Revista Brasileira de Zootecnia, v.30, n.3, p.835-843, 2001.

SHORT, R.E.; BELOWS, R.A. Relationship among weight gains, age at puberty and reproductive performance in heifers. Journal of Animal Science, v.32, n.5, p.1964-197, 1971.

VARNER, L.W.; BELLOWS, R.A.; CHRISTENSEN, D.S. A management system for wintering replacement heifers. Journal of Animal Science, v.44, n.2, p.165-171, 1977.

WILTBANK, J.N. Changing reproductive performance in beef cows herds. In: ANNUAL CONFERENCE ON ARTIFICIAL INSEMINATION AND EMBRYO TRANSFER, 1985, Denver Proceedings... Coolumbus: National Association of Animals Breeders, 1985. p.15-27 